\title{
Case Study of Pump Failure Due to Rotor-Stator Interaction
}

\author{
HIDEO OHASHI \\ Professor, Kogakuin University, Tokyo, Japan
}

\begin{abstract}
Fluiddynamic interaction between rotor and stator generates local pressure fluctuation and can be a cause of structural vibration of turbomachines. The interaction produces a spatial distribution of pressure fluctuation with a certain diametrical mode and propagating speed, known as rotating pressure field. When the frequency and mode of a rotating pressure field coincide with those of the structural vibration, a fluid-excited resonance takes place, leading to eventual severe structural damage. An example of such damage is described in detail using the case of PLR pump failure of a BWR plant.
\end{abstract}

Key Words: Rotor; Stator; Interaction; Damage; Pump; BWR

$\mathbf{T}$ HE function of fluid machinery is to transfer shaft power to fluid energy, or vice versa, with the highest possible efficiency. The priorities of design considerations are therefore laid on reducing fluid losses in flow elements like impellers and diffusers. Even a turbomachine with a superior performance becomes useless if its operational stability or reliability is insufficient, for example, due to noise, vibration, erosion, corrosion, or fluctuating stress of an excessive level. The latter obviously results in a fatigue fracture of corresponding structure.

Fluiddynamic interaction between moving impeller blades (rotor) and stationary guide vanes (stator), hereafter called rotor-stator interaction, is an inherent phenomenon in turbomachines. This interaction produces local unsteady flow in the turbomachine and is the cause of noise or pressure fluctuation that is transmitted far away from the machine. The interaction is also the source of fluctuating fluid force on internal structures such as impeller and diffuser and could induce a severe structural vibration if the excitation mode and frequency match with those of the structure.

Rotor-stator interaction is a well-known phenomenon. Its fundamental frequency of excitation to a stationary structure is determined by the number of passing blades per unit time, that is, so-called blade-passing frequency.
Fluctuation in a stationary system is excited solely by passing impeller blades and has nothing to do with the number of stationary vanes. Pressure fluctuation in a diffuser, a typical stationary structure, obviously has frequency components of blade-passing frequency and its higher harmonics. The spatial distribution of this fluctuation in the diffuser can be represented by the superposition of a set of rotating pressure fields, as proved first by Tyler and Sofrin [1962], using the concept of spinning lobe.

When the frequency and mode of a rotating pressure field coincide with those of the structural vibration, a fluid-excited resonance takes place, leading to eventual severe structural damage. This interpretation of rotor-stator interaction has attracted little attention and recognition in the past. The main purpose of this paper is to provoke a renewed attention to this aspect. A detailed case study is given for the structural failure of a Primary Loop Recirculating (PLR) pump of a Boiling Water Reactor (BWR) plant.

Vibration of turbomachines caused by rotating pressure field has been reported in few articles. The relevant problems in hydraulic turbines were reported in detail by Tanaka et al. [1990, 1992a, 1992b]. The report on PLR pump failure by Ohashi [1991] gave a typical example of centrifugal pumps. 


\section{ROTOR-STATOR INTERACTION}

First we consider the case in which an impeller with $Z_{r}$ number of blades is rotating with rotational speed $N$ in a free space like a sufficiently large vaneless diffuser. The relative flow in the impeller is in this case steady. However, the absolute flow observed, for instance, near the impeller exit is unsteady and contains periodic fluctuation due to the passing of impeller blades. The fundamental frequency is equal to blade passing frequency $Z_{r} N$.

If the impeller is installed in a vaned diffuser with $Z_{g}$ number of guide vanes or in a volute with $Z_{g}$ number of volute tongues, the relative flow in the impeller becomes no more steady. It contains periodic fluctuation of frequency $Z_{g} N$ excited by the relative passing of stationary vanes. This is also blade-passing frequency seen from the rotating coordinate fixed to the impeller.

As the above description indicates, the absolute flow observed in stationary system contains velocity and pressure fluctuations of fundamental frequency $Z_{r} N$ superimposed with its higher harmonics. On the other hand, the relative flow observed in rotating system or in impeller contains those of fundamental frequency $Z_{g} N$ superimposed with its harmonics. As far as fluctuation frequency is concerned, the principle of rotor-stator interaction is quite simple, however, the spatial distribution of the above fluctuation has attracted little attention in the past.

\section{ROTATING PRESSURE FIELD}

Now let's consider how pressure fluctuation due to rotorstator interaction is formed and changes its location every moment, using a concrete example of Figure 1. The figure indicates the case in which an impeller with eight blades, $Z_{r}=8$, rotates counterclockwise in a diffuser with six guide vanes, $Z_{g}=6$, where all blades and vanes are represented simply by radial lines. When the trailing edge of a moving blade passes nearby the leading edge of a guide vane, a pressure pulsation, say positive pressure, is generated in the vicinity, which is indicated by a black hill in the figure. In the case of $Z_{r}=8$ and $Z_{g}=6$, there are two simultaneous encounters of rotor and stator on the periphery and they are indicated by two black hills $180^{\circ}$ apart from each other. (The above example is reproduced from the original figure of Tyler and Sofrin [1962].)

The seven sequential patterns, \# 0 to \# 6 , of the figure indicate how the black hills, representing positive pressure pulsation, propagate as the impeller rotates every $1 / 24$ of a rotation. As seen from the sequence of the patterns, the pressure field of $\# 6$ has completed a full counter-clockwise

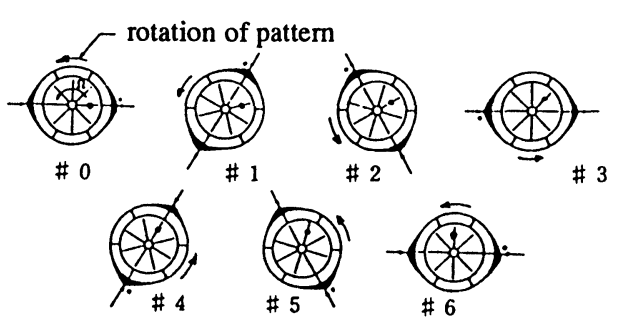

FIGURE 1 Generation of rotating pressure field, case of $Z_{r}=8$ and $Z_{g}=6$.

rotation while the impeller rotates a quarter of a rotation. In conclusion, the pressure field with two positive peaks rotates in the diffuser four times faster than and in the same direction as the impeller rotates. This pressure pattern with two positive peaks in circumferential distribution, in other words, with two negative peaks, is called the 2 nd-order diametrical mode (mode with two diametrical nodal lines).

For an arbitrary combination of the numbers of rotors and stators, $Z_{r}$ and $Z_{g}$, the order of diametrical mode of induced pressure field, its rotational speed and the direction of rotation can be determined by using the graphical method as explained above. The same result can be obtained also by a mathematical theory on the superposition of perturbations and is known as the generation law of spinning lobe by Tyler and Sofrin [1962], which provided a theoretical basis for the noise radiation from axial turbomachines.

Kubota et al. [1983] modified the above generation law to the form that is more convenient for the application to radial turbomachines and is more physically comprehensible both for stationary and rotating systems. The generation law of rotating pressure fields is given by:

$$
n Z_{g}+k=m Z_{r}
$$

where;

$k$

is the order of diametrical mode (integer); $k>0$ rotates in the same direction as impeller (forward propagating wave); $k<0$ rotates in the opposite direction as impeller (backward propagating wave)

$n$ is the order of excitation harmonics in rotating system (positive integer)

$f_{r}=n Z_{g} N \quad$ represents the fluctuation frequency in rotating system $(\mathrm{Hz})$

$f_{p r}=f_{r} / k \quad$ represents the rotational speed of pressure field in rotating system $(\mathrm{Hz})$

$m$ is the order of excitation harmonics in stationary system (positive integer)

$f_{s}=m Z_{r} N \quad$ is the fluctuation frequency in stationary system $(\mathrm{Hz})$ 
$f_{p s}=f_{s} / k \quad$ is the rotational speed of pressure field in stationary system $(\mathrm{Hz})$

When we apply the above law to the sample case of $Z_{r}=8$ and $Z_{g}=6$, we obtain $k=+2$ (2nd diametrical mode forward wave) for the fundamental excitation of $n=1$ and $m=1$. The rotational speed of pressure field in stationary system is thus $f_{p s}=f_{s} / k=\left(m Z_{r} / k\right) N=+4 N$ and coincides with the prediction by Figure 1. The rotational speed of pressure field in rotating system (relative speed) is $f_{p r}=f_{r} / k=\left(n Z_{g} / k\right) N=+3 N$, also in the same direction as the impeller rotates.

When we consider higher harmonics, $n=2,3, \ldots$ and $m=2,3, \ldots$, there exist quite a number of rotating pressure fields. For the combination of $Z_{r}=8$ and $Z_{g}=6$, the above law allows such modes as $k=+6(m=3, n$ $=3), k=+4(m=2, n=2), k=+2(m=1, n$ $=1), k=0(m=3, n=4), k=-2(m=2, n=$ $3), k=-4(m=1, n=2), k=-6(m=3, n=5)$ and so on. If there are forward and backward waves with the same diametrical mode and frequency, the superposition of the two waves constitutes a standing wave.

The real pressure field induced by rotor-stator interaction is the superposition of permissible rotating pressure fields with corresponding mode, frequency, and intensity. The intensity of excitation decreases generally as the order of harmonics increases. Therefore, there are only limited number of significant rotating pressure fields, which should be taken into consideration in a given practical problem.

As explained above, rotor-stator interaction induces a set of rotating pressure fields in stationary system, that is, in diffuser, volute, and casing. If there is a stationary structure, which has a vibration mode with the same order of diametrical mode and natural frequency as those of an excited pressure field, there occurs a fluid-excited structural resonance. Unless a sufficient damping is provided, such structural resonance may result in a structural failure due to fatigue fracture. The natural frequency of structure is, of course, the value at operating condition under the added mass effect of surrounding fluid.

\section{CASE STUDY OF THE FAILURE OF A PLR PUMP}

\section{Description of the Event}

The event took place on January 1, 1988, when Unit No. 3 of Fukushima No. 2 Nuclear Power Station (four 1,100 MW BWR units) was operating at an output of 1,030 MW. An annunciator in the central control room triggered at
7:02 P.M. and indicated that the vibration level of the motor of PLR pump B (one of two) exceeded the setpoint. The operator followed the operational manual and lowered the speed of the pump from $87 \%$ to $85 \%$ of the rating, until the vibration level sank below the setpoint. The unit then continued operation at $990 \mathrm{MW}$ under closer monitoring of relevant parameters. The vibration level fluctuated in an unstable manner from time to time but stayed always below the alarm level.

On January 6 at 4:20 A.M. the vibration increased again and triggered the annunciator. The pump speed was again gradually lowered until the plant output decreased to 740 MW but the vibration indicated no improvement and kept on at a high level. At noon of that day the plant operation was finally abandoned and manual shut down procedures of the reactor started immediately. The PLR pumps were stopped at 6:55 P.M., the generator disconnected at 12:00 midnight and the reactor was shut down at 3:47 A.M. of the next day.

Since the plant outage for its 3rd periodical inspection was planned originally a few days later, the unit went into its periodical inspection on the same day, January 7, and the PLR pump of loop B was disassembled for inspection. It was found that the bearing ring welded to hydrostatic bearing fell off completely and was broken into two fragments. Damages of various internal parts of the pump were also observed. Moreover, it was confirmed that a voluminous amount of metallic particles and powders, totaling about $30 \mathrm{~kg}$, had flown away and scattered in the reactor pressure vessel, fuel assemblies, and piping systems.

A special investigating committee on this event was set up in the Agency of Natural Resources and Energy of MITI [1990a, 1990b] with the missions to clear the cause of the failure, to establish countermeasures, and to evaluate the soundness of the reactor for restart. After enormous efforts to repair and clean up the system, to clear regulatory procedures, and to restore public acceptance of the plant, the unit went into commercial operation at the end of 1991. The fracture of a small ring forced the giant power unit into standstill mode for two full years. The technical details described in this paper are all referred from the documents made public by the Agency [1990a, 1990b].

\section{Structure of PLR Pump}

Figure 2 illustrates the cut view of a PLR pump, which is used to sustain a controlled recirculating cooling flow in the reactor core of BWR plant. A pair of PLR pumps suck reactor water $\left(70 \mathrm{~atm}, 280^{\circ} \mathrm{C}\right)$ from the bottom of the reactor vessel and feed it back to ten jet pumps in the vessel as primary (driving) water, which, along with 


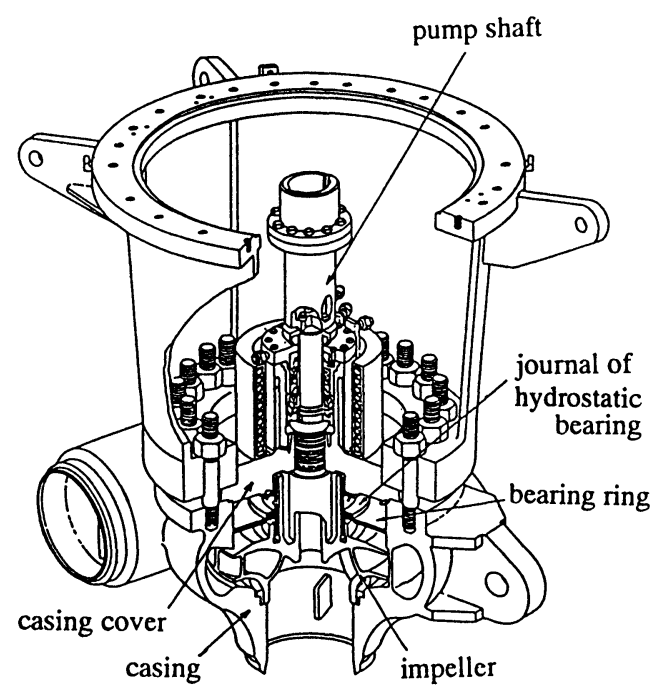

FIGURE 2 Cut view of PLR pump.

induced secondary water, sustains a strong recirculating flow in the reactor core. PLR pump is a vertical-shaft, single-stage centrifugal pump with double volute casing and is driven by a variable-speed induction motor of 6,800 $\mathrm{kW}$. The pump operates at rotational speed between 20 and $100 \%$ of its rating, $1,395 \mathrm{rpm}$.

The motor shaft is supported by journal and thrust bearings and is connected solidly to the pump shaft. The impeller is mounted overhung at the lower shaft end. To suppress vibration of the impeller, a water-lubricated hydrostatic bearing is installed in the pump casing, as illustrated in Figure 3. This bearing utilizes the pressure difference between pump discharge and suction to sustain it hydrostatic force.

The space surrounded by the back shroud of the rotating impeller, pump casing, and bearing journal is filled with discharged water. As seen from the figure, a flat ring is welded to the bearing journal and separates the enclosed space into upper and lower chambers. Since the water in the upper chamber is supplied through a narrow gap (6.65 $\mathrm{mm}$ ) between ring and casing, it is almost in standstill and can supply stable lubricating water to eight bearing pockets through matching feed holes. To the contrast, the water in the lower chamber is dragged by the friction of the rotating back shroud and is whirling at about half the rotating speed on average. The water in this chamber also receives flow and pressure disturbances directly from the pump discharge. This partition ring, the cause of the later structural failure, is installed to ensure a stable lubrication of the bearing.

The pressure in the upper chamber is constant because

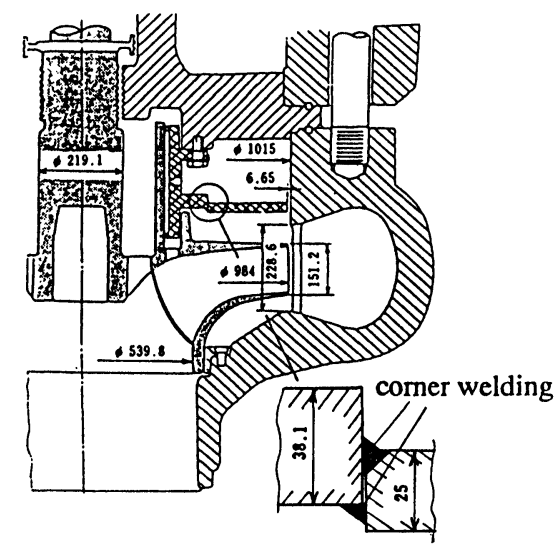

FIGURE 3 Cross-section of PLR pump.

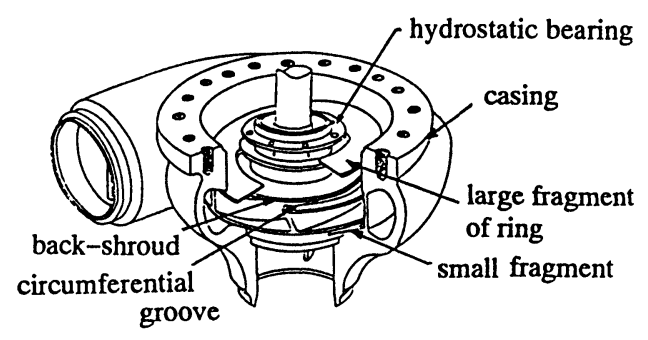

FIGURE 4 Damaged pump found after dismantling

the water is in standstill. On the other hand, the pressure in the lower chamber decreases toward the center due to the rotation of water. Since the pressure of each chamber coincides at the outer radius due to the gap connecting them, the ring receives downward thrust and additional fluctuating load due to rotor-stator interaction. At the design stage of this pump, all these loads to the ring were estimated and the conclusion was that continuous corner welding along upper and lower junction corners as shown in the figure was sufficient to fix the ring to the bearing journal.

\section{Damages Found after the Failure}

Figure 4 illustrates the condition of the pump after the failure occurred. The ring was completely separated from the bearing journal along the welding lines and was further broken apart into two, i.e., large (4/5) and small (1/5) fragments. The large fragment just fell down and remained on the back shroud of the impeller, while the small one was found between the front shroud and pump casing. On the back shroud a concentric groove penetrating all the way through the thickness was found at about $85 \%$ of the outer diameter.

The outer annulus, separated from the remaining back 


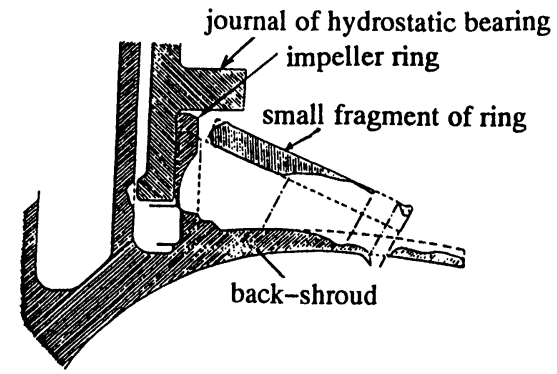

FIGURE 5 Cause of groove formation on back shroud.

shroud by the groove, was connected to the impeller by five blades and kept its original location for a while. When one of five spans of the annulus was broken and had flown away, the impeller lost finally its balance and was forced to quit the operation.

The mechanism of groove formation on the back shroud could be estimated from Figure 5. The cross-section of the broken small fragment coincides exactly with that of back shroud as the figure indicates. This replica formation suggests that small fragments first sat quietly in inclined position on the rotating back shroud and they continued to rub each other, presumably, over four days, until the wear dug out a groove penetrating the whole shroud thickness. All this wear debris was scattered and diffused in the reactor water as fine metal powder.

\section{Cause of the Failure}

The investigation after the event proved that the cause of the fracture is the resonance of bearing ring with rotating pressure field. Figure 6 demonstrates the simplest case of such resonance. If the rotating pressure field in stationary system, shown in the figure as the 1st diametrical mode (single nodal line) of frequency $f_{p s}$, and vibration mode of the ring, also the 1st diametrical mode of natural frequency $f_{s t}$, have the same frequency, $f_{p s}=f_{s t}$, and the same direction of propagation, fluid/structure resonance of this mode takes place. If the fluctuating stress exceeds fatigue limit, a fracture due to crack propagation will be resulted after definite operating hours.

Figure 7 shows the vibration mode of the bearing ring with the 0th, 1st, 2nd, and 3rd diametrical modes. Listed also are natural frequencies of the ring measured in air, measured in pump casing filled with water, and the calculated values obtained by numerical simulation. For the numerical analyses, calculations of structural deformation and associated unsteady potential flow around the ring were conducted simultaneously, so that the added mass on the ring could be taken exactly into consideration. As the

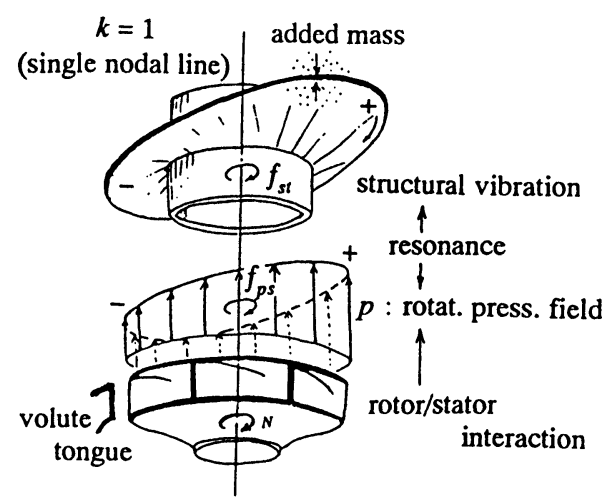

FIGURE 6 Fluid/structure resonance, $k=1$.

large difference between natural frequencies in air and in water indicates, the effect of added mass is quite significant for the natural frequency of a structure submerged in enclosed water. The exact estimation of added mass is therefore of primary importance for the numerical simulation.

When the ring vibrates in the casing filled with still water, the natural frequencies of forward- and backwardpropagating waves are equal. In reality, however, the water in the lower chamber is dragged by the rotating back shroud and rotates roughly at about half the rotational speed. This rotation results in the decrease of added mass to forward wave, and the increase to backward wave. Consequently the natural frequency of forward wave becomes higher than that of backward wave. Kubota and Ohashi [1991] analyzed this phenomenon and obtained the following relation:

$$
\left(f_{a} / f_{w}\right)^{2}=1+(1-k a)^{2} M_{l}+M_{u}
$$

where;

$f_{a} \quad$ is the natural frequency in air (no add-

ed mass)

$f_{w} \quad$ is the natural frequency in water

$k \quad$ is the order of diametrical mode

$a=$ nearly 0.5 rotational speed of water in lower chamber relative to the impeller rotation

$M_{u}, M_{l} \quad$ the added mass parameter of water in upper and lower chamber under standstill condition.

$M_{u}, M_{l}$ are equal in the present case and the value can be determined by measuring $f_{a} / f_{w}$ at $a=0$ (in still water).

Figure 8 shows the geometry of double volute casing, in which the impeller with five blades rotates. Since the volute is equivalent to a diffuser with two guide vanes, the rotor-stator interaction of the present case is obtained 


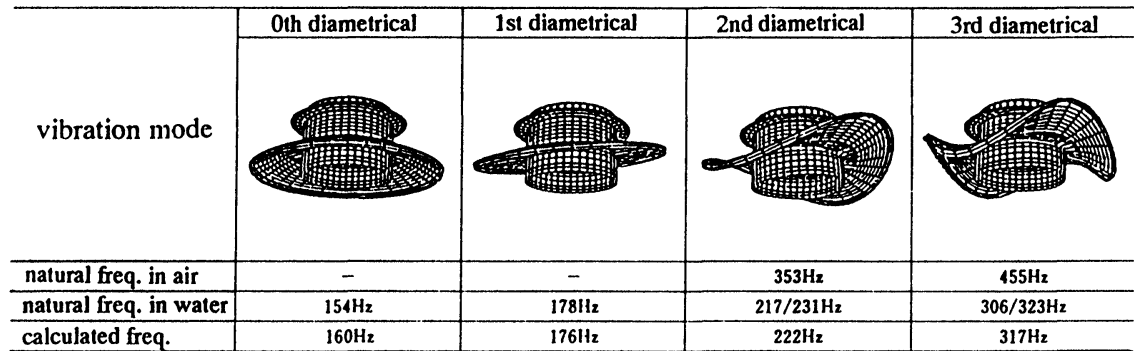

FIGURE 7 Vibration mode of bearing ring.

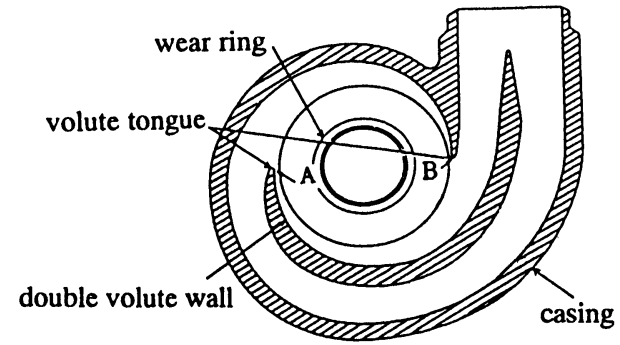

FIGURE 8 Volute casing of PLR pump.

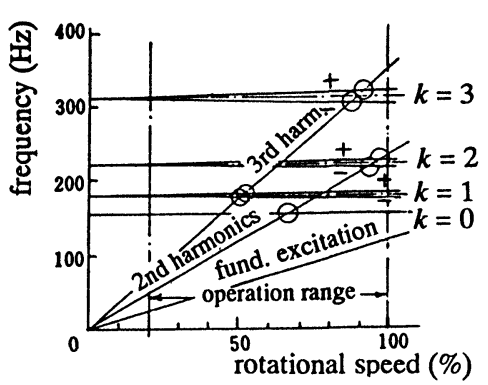

FIGURE 9 Campbell diagram.

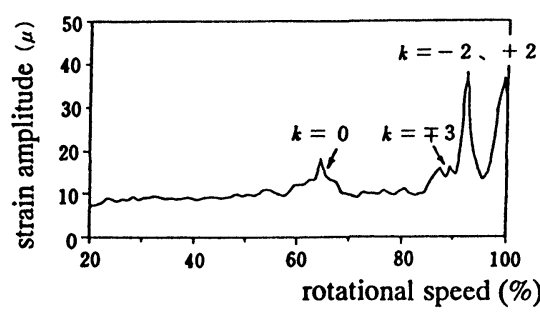

FIGURE 10 Measured stress of bearing ring.

For $m=2$ (2nd higher harmonics):

Figure 9 represents the Campbell diagram, in which natural frequencies of the ring (for $k=0, \pm 1, \pm 2$ and \pm 3 ) and excitation frequencies (of fundamental, 2nd- and 3rdorder harmonics) due to rotor-stator interaction are plotted against pump rotational speed. Since odd (or even) order harmonics excites vibration of odd (or even) order diametrical mode, the crossings indicated by circles represent possible fluid/structure resonances. The strain measured near the corner welds of the ring is plotted in Figure 10 over the operating speed range of $20 \%$ to $100 \%$ of the rating. The observed peaks of strain fluctuation correspond to the resonance of indicated diametrical mode and coincide with the prediction by the Campbell diagram. The resonance that caused the failure of the PLR pump was $k=-2$ mode (2nd diametrical mode, backward wave) and occurred at $92 \%$ of rating speed, the speed range most frequently used during plant operation. 
Since the resonance was in a propagating mode, upper and lower corner welds of the ring were exposed to the same stress along the whole periphery. Metallurgical investigation with fractography indicated that the fatigue crack was initiated and propagated first in the lower weld and a subsequent crack propagation followed in the upper weld, thus leading to a perfect breakaway of the ring from the journal.

\section{Countermeasures}

The best solution is to avoid such fluid/structure resonance beforehand. In many cases, however, especially for variable-speed turbomachines, it becomes impossible to avoid every resonance in the operational speed range. The remedy in this case is either to reduce the stress level below fatigue limit by structural improvement or to increase damping to reduce the strain at resonance. The damaged PLR pump was so improved that the ring was connected to the bearing journal by full penetration welding instead of corner welding, thus drastically reducing the stress level during resonances.

\section{LESSONS LEARNED FROM THE EVENT}

Accident is the mother of progress. The pump failure described above bestowed the following lessons on us:

1. Listen carefully to the warnings of nature. Don't overlook any indications. Before the described pump failure occurred, damage of the bearing ring had been experienced twice. This was discovered during periodical inspections of PLR pumps of the same type. In one case, a small fraction of the ring fell down and was found on the back shroud of impeller. In the other case, cracks were found in the corner welds. In both cases the cause of the damage was attributed to a trivial defect of welding, while the real enemy-the resonance-was overlooked. Our knowledge on what we have built is limited. It is essential to listen carefully to messages that might be transmitted from any ailing parts.

2. Proving tests can't prove everything. In order to verify the reliability and soundness of key components of Light Water Reactors, a series of proving tests had been conducted under governmental support. The troublestricken PLR pump was included, of course, in the project, and an extensive proving test had been completed before the failure. A full-scale PLR pump was tested under the reactor temperature and pressure condition for over 4,000 hours and no mentionable problems had been found at all. After the failure happened, a blind spot of the proving test was seen. The pump was driven by a variable-speed motor and operated between $20 \%$ and $100 \%$ of the rating speed. It was assumed that the most severe test condition for the pump was to operate it at the maximum speed. Therefore the majority of the test was conducted at $100 \%$ of the rating speed. As described above, the resonance of the bearing ring occurred at around $92 \%$ of the rating speed.

Variable-speed turbomachines are very tricky objects for proving or verification tests. It is hardly possible to detect eventual resonances of every internal structure enclosed in a heavy casing wall. We can sweep the rotational speed of the pump over the operational range but the detection of resonance from outside is impossible. It is also impossible to install vibration sensors (strain gauge, accelerometer, or gap sensor) to every internal structure. Only long operational experience can tell us the reliability and soundness of the machine. Any kind of proving test can assure only within the test items, just as the diagnosis of a doctor- "you are quite healthy"-really means "no problem is found in the inspected items". An unreserved guarantee is merely an illusion.

3. Stiffness doesn't mean strength. Let's compare a large solid bronze bell and a small wooden drum, both found in a Buddhist temple. If you strike the bell, it generates a beautiful-sounding gong, lasting for several seconds. To the contrary, the wooden drum sounds oncepock! - and that's all. Which seems stronger against fracture? The majority would judge for the former. Now we set the bell on a shaking stand. If we tune the shaking frequency so as to coincide with the natural frequency of the bell, the bell will be brought to a resonance and start to generate formidable sound. Since the material damping of the bell is very low, the vibration stress of the bell at the resonance will exceed its fatigue limit and the growth of crack will destroy the bell in a relatively short time. The wooden drum, with a large internal damping, will never be destroyed by resonance. If once resonance takes place, the fate is determined not by the stiffness but by the damping. Stiffness and strength against fracture are different matter.

4. Structure/fluid coupled vibration analysis is an indispensable tool. In order to avoid possible fluid/structure resonances in turbomachines, designers should have tools to evaluate vibration mode and frequency of relevant structures. Nowadays, powerful tools for FEM analyses are available on the market and the eigen modes and frequencies of a complicated structure can be estimated without much difficulty, so far as the structure vibrates in air. In hydraulic machinery, a vibrating structure induces an associated unsteady flow of surrounding water and gets a substantial reaction from the water through a well-known added mass effect. As the example of Figure 7 indicates, the decrease of eigen frequencies in water is quite substan- 
tial, reaching a $40 \%$ to $50 \%$ decrease in extreme cases. To take the effect of added mass exactly into account, structural vibration and associated fluid flow must be calculated simultaneously in a coupled way. This is quite time consuming and an elaborate task but is a kind of required subject for turbomachine designers.

5. Measurement deserves its cost and labor. For variable-speed turbomachines, it is practically impossible to avoid every resonance in the whole operating speed range. The concern in this case is whether the stress level stays below an acceptable level. The vibration stress under resonance condition depends on the intensity of fluid excitation and the internal damping of the structure, both extremely difficult to evaluate analytically. Therefore, evaluation of strees at resonance condition is hardly possible by any analytical approach available today. Only measurement using a prototype or a model machine can answer this question. Measurement is therefore indispensable and the result can also be used as the tuning data for future analytical modeling.

\section{CONCLUSION}

Rotor-stator interaction is reviewed from the viewpoint of rotating pressure field. The generation law of rotating pressure field is given and its physical interpretation is introduced. As an example of the resonance of pressure field with a stationary structure, a detailed case study was discussed on the failure of a PLR pump.

\section{References}

Agency of Natural Resources and Energy (MITI), 1990a. Report on the Failure of PLR Pump of No. 3 Unit of Fukushima No. 2 Nuclear Power Station, Cause and Countermeasures, February (in Japanese).

Agency of Natural Resources and Energy (MITI), 1990b. Report on the Failure of PLR Pump of No. 3 Unit of Fukushima No. 2 Nuclear Power Station, Estimation of Reactor Soundness, July (in Japanese).

Kubota, Y., and Ohashi, H., 1991. A Study on the Natural Frequencies of Hydraulic Pumps, Proceedings of the 1st JSME/ASME Joint International Conference on Nuclear Engineering, pp. 589-593, Tokyo.

Kubota, Y. et al., 1983. Vibration of Vaned Disks Due to Distributed Excitation Sources in Stationary System, Transaction of the JSME, Series C. 49-439, pp. 307-313 (in Japanese).

Ohashi, H., 1991. Example of Pump Failure Due to Rotor/Stator Interaction, Turbomachinery, No. 6, pp. 348-355 (in Japanese).

Tanaka, H., 1990. Vibration Behavior and Dynamic Stress of Runners of Very High Head Reversible Pump Turbines, Proceedings of the IAHR Symposium 1990, Beograd, Special Book U2.

Tanaka, H. et al., 1992a. Vibration Stress of Runners of Reversible Pump Turbines for Very High Head, Part 1, Turbomachinery, No. 8, pp. 479_ 486 (in Japanese).

Tanaka, H. et al., 1992b. Vibration Stress of Runners of Reversible Pump Turbines for Very High Head, Part 2, Turbomachinery, No. 8, pp. 563568 ( in Japanese).

Tyler, J. M., and Sofrin, T. G., 1962. Axial Flow Compressor Noise Studies, Transactions of the SAE, Vol. 70, pp. 309-332. 

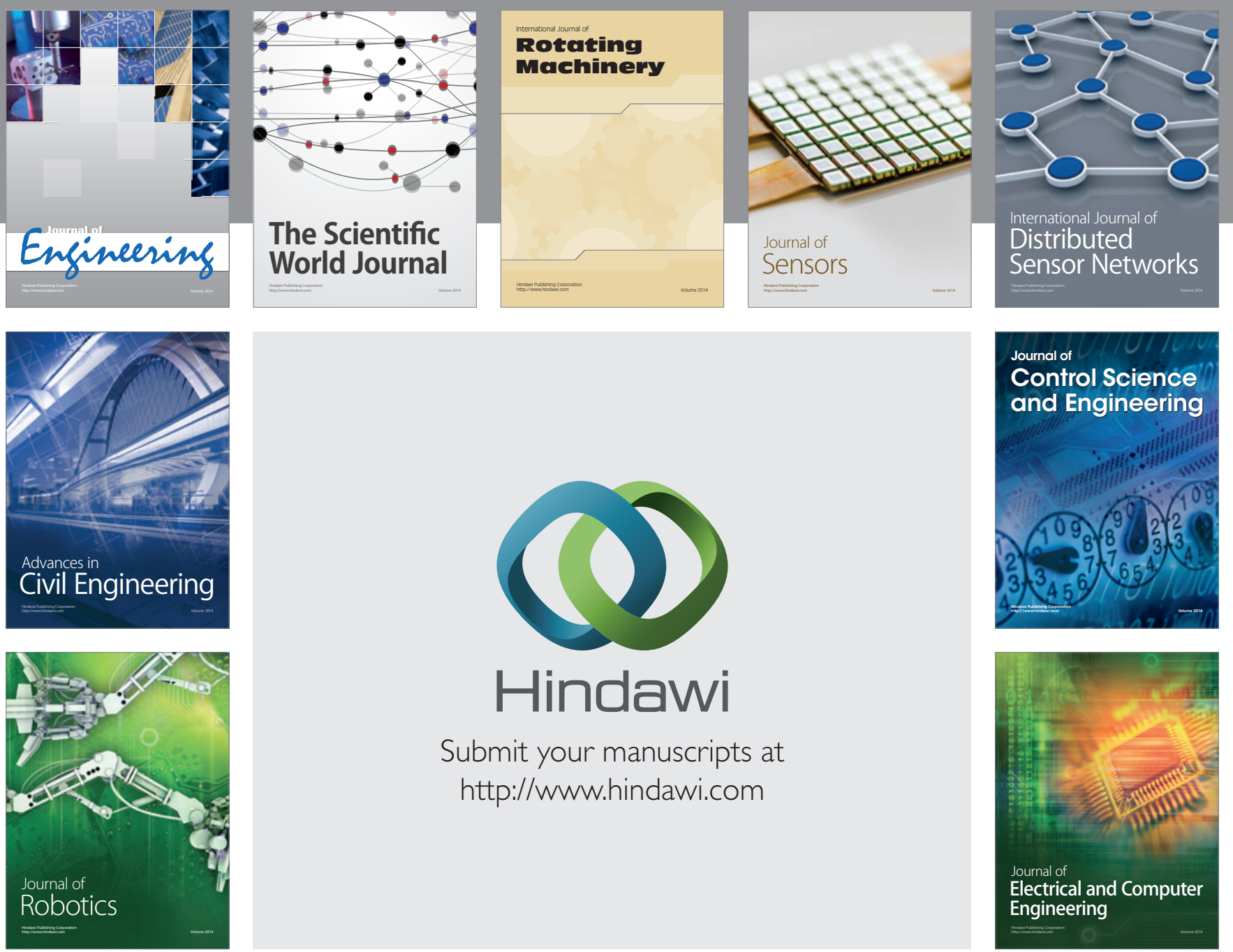

Submit your manuscripts at

http://www.hindawi.com
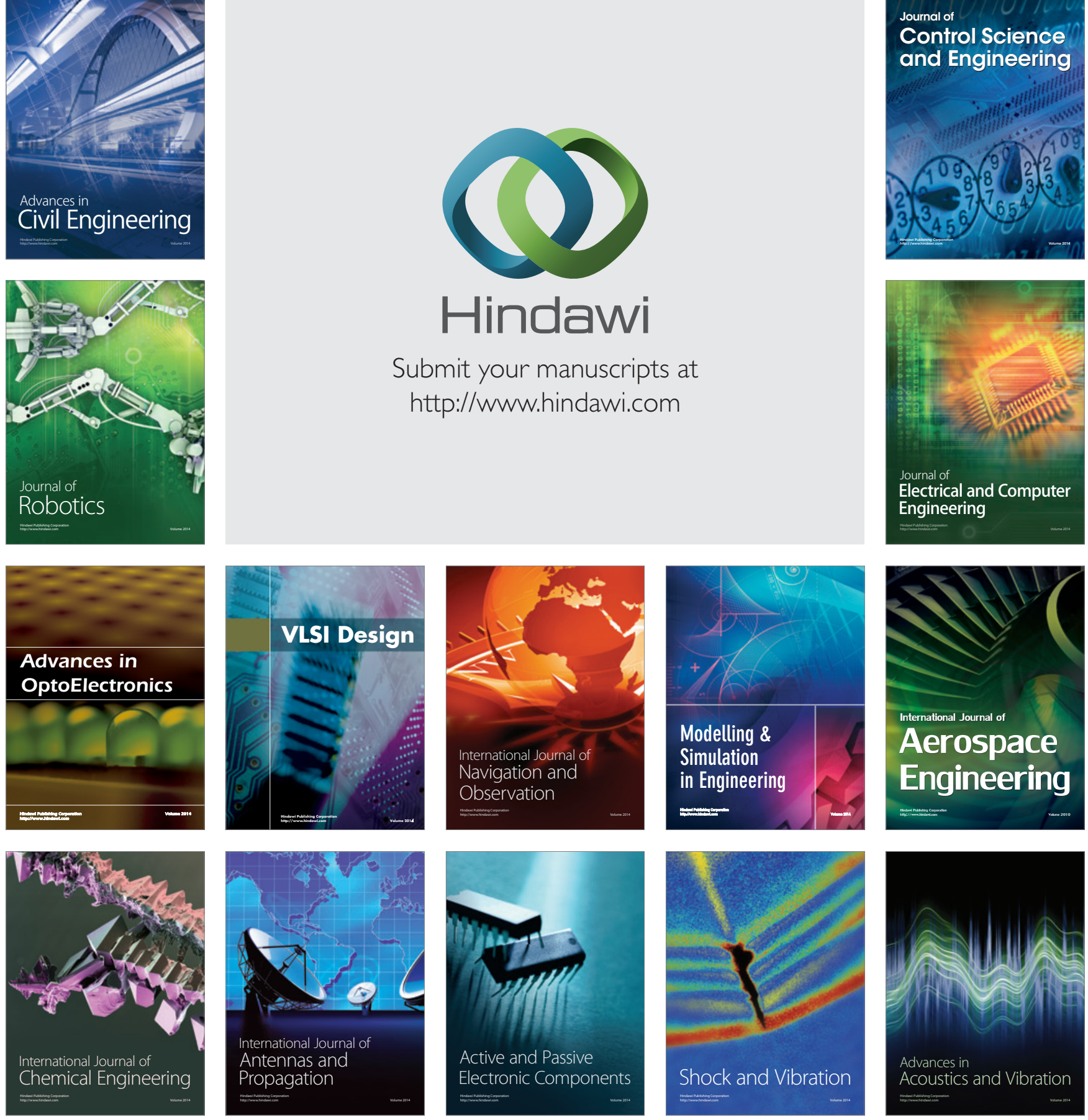